\title{
Corrigendum
}

\section{An Improved Electron Microprobe Method for the Analysis of Halogens in Natural Silicate Glasses - CORRIGENDUM}

\author{
Stamatis Flemetakis ${ }^{1}$, Jasper Berndt ${ }^{1}$, Stephan Klemme ${ }^{1}$, Felix Genske ${ }^{1}$, Anita Cadoux ${ }^{2}$, Marion Louvel ${ }^{1}$ \\ and Arno Rohrbach ${ }^{1}$ \\ ${ }^{1}$ Institut für Mineralogie, Westfälische Wilhelms-Universität Münster, Corrensstraße 24, 48189 Münster, Germany and ${ }^{2}$ Independent Scholar, Orsay, France
}

doi: https://doi.org/10.1017/S1431927620013495, Published by Cambridge University Press, 10 August 2020

The affiliation for author Anita Cadoux has been corrected since original publication. The corrected affiliation appears in the above byline.

\section{Reference}

Flemetakis S, Berndt J, Klemme S, Genske F, Cadoux A, Louvel M, and Rohrbach A (2020) An Improved Electron Microprobe Method for the Analysis of Halogens in Natural Silicate Glasses. Microsc Microanal 26(5), 857-866. doi:10.1017/S1431927620013495. 